\title{
Gestação e maternidade em cárcere: cuidados de saúde a partir do olhar das mulheres presas em uma unidade materno-infantil
}

\section{| ${ }^{1}$ Luana Hordones Chaves, ${ }^{2}$ Isabela Cristina Alves de Araújo |}

Resumo: Este artigo apresenta resultados de uma pesquisa realizada na unidade prisional materno-infantil do Estado de Minas Gerais. Com o objetivo de tratar das impressōes que as mulheres presas no Centro de Referência à Gestante Privada de Liberdade (CRGPL) têm acerca dos cuidados de saúde ofertados pela instituição, foram analisados os dados processados a partir da realização de entrevistas semiestruturadas e da aplicação de questionários estruturados. A pesquisa ocorreu no ano de 2017, e a análise proposta neste estudo é guiada pela compreensão do conceito de saúde a partir do tripé "social, psicológico e assistência ao cuidado com a saúde", na perspectiva das representaçóes sociais. Como resultado, tem-se uma avaliação em certa medida positiva dos cuidados de saúde na perspectiva das gestantes e recém-mães do Centro, e isso é muito marcado, segundo os relatos, pelas experiências prisionais anteriores das entrevistadas. Por outro lado, alguns problemas enfrentados no CRGPL foram levantados pelas internas, e descritos como fonte de diversos sofrimentos.

> Palavras-chave: saúde; maternidade; gestação; prisão feminina.

\author{
1 Universidade Federal de Minas \\ Gerais, Sociologia. Belo Horizonte- \\ MG, Brasil (luanahordonechaves@ \\ hotmail.com). \\ ORCID: 0000-0003-4301-3307 \\ ${ }^{2}$ Universidade Federal de \\ Minas Gerais, Sociologia. \\ Belo Horizonte-MG, Brasil \\ (isabelacristina1903@gmail.com) \\ ORCID: 0000-0002-2526-4825
}

Recebido em: 20/02/2019

Aprovado em: 10/10/2019 Revisado em: 21/01/2020 


\section{Introdução}

Na vida da mulher a gestação significa, além de um momento bastante peculiar, um momento que requer muitos cuidados de saúde. Quando a vida no cárcere e a gestação se entrecruzam, fica latente a vulnerabilidade da mulher, sendo necessário entâo um olhar atento para suas necessidades e suas especificidades. Tendo em vista isso, e considerando o aumento do número de mulheres no contexto prisional brasileiro, questôes referentes à saúde da mulher gestante começaram a fazer parte das políticas públicas nacionais ${ }^{1}$.

O Plano Nacional de Saúde no Sistema Penitenciário foi o primeiro esforço, ainda incipiente, que elucidava a necessidade de "realização do pré-natal, controle do câncer cérvico-uterino e de mama" (BRASIL/MS, 2004, p. 30). Anos depois, a discussão sobre a maternidade entrou de fato em pauta, com a criação da Lei no 11.942/2009, que alterou a Lei de Execução Penal de 1984, ressaltando então os direitos das encarceradas, principalmente a necessidade da proteção diferenciada e qualificada ao cuidado materno-infantil. É, portanto, a lei de 2009 que garante o acesso à saúde às gestantes, assegurando a assistência integral à saúde da mulher que está grávida em situação de privação de liberdade, e ao seu bebê após o nascimento. Há, a partir de então, uma preocupação com relação à presença dos filhos nas penitenciárias e com os direitos das mães e de seus bebês após o nascimento. Ao considerar a presa grávida, a lei diz que "será assegurado acompanhamento médico à mulher, principalmente no pré-natal e no pós-parto, extensivo ao recém-nascido" (BRASIL, 2009, Art. 14).

$\mathrm{O}$ contexto mineiro merece destaque nesta discussão. Antes mesmo da aprovação da lei supracitada, a preocupação com a salubridade do local em que as mulheres grávidas e lactantes cumpriam pena e com a oferta de serviços de saúde nas instalaçôes prisionais levou o estado a inaugurar o Centro de Referência à Gestante Privada de Liberdade (CRGPL) na Região Metropolitana de Belo Horizonte. Minas Gerais foi, assim, considerado pioneiro no compromisso de prestar atenção qualificada em saúde às mulheres que cumpriam pena durante a gestação. Tendo em vista que o CRGPL é a primeira unidade idealizada para garantir o acesso à saúde integral à mulher gestante e ao seu filho até completar o primeiro ano de idade e para promover a manutenção do vínculo da mãe com a sua criança, o Centro é reconhecido como modelo na assistência à saúde materno-infantil no Brasil, e no atendimento a essa população carcerária específica. 
Se, no momento da inauguração, fazia sentido pensar em uma estrutura de qualidade para receber as presas gestantes e mães com seus filhos, com o avançar da discussão política e acadêmica — guiada por Braga et al. (2015a) — as preocupaçôes se tornaram outras. Tendo em vista as violaçôes de direitos e as consequências da experiência do aprisionamento, o desencarceramento de mulheres gestantes e máes tem sido o principal tema de debates políticos acerca do sistema prisional feminino no país. Esse movimento se deu primeiramente com a aprovação da Lei no 13.257 em 2016, nomeada como "Marco Legal da Primeira Infância”, que traz a possibilidade de o juiz substituir a prisão provisória pela prisão domiciliar tanto para as mulheres gestantes quanto para as com filhos até 12 anos, salvo aquelas que estejam sendo julgadas por crimes contra crianças. E, no segundo momento, com o habeas corpus coletivo, concedido em 2018 pelo Supremo Tribunal Federal a todas as gestantes e mães encarceradas nessas condiçóes.

Apesar da recente legislação, são muitas mães e filhos que poderiam ser beneficiados pela lei de 2016, mas continuam vivendo o cárcere no Brasil. E essa é a realidade do nosso estudo: mulheres gestantes e recém-mães que se encontram encarceradas em Minas Gerais, mesmo que muitas tenham direito à prisão domiciliar. Assim, o objetivo deste trabalho é tratar das impressões que as mulheres presas nesta unidade prisional materno-infantil têm acerca dos cuidados com saúde ofertados pela instituição. A partir de uma abordagem qualitativa e quantitativa, o artigo busca compreender o que as internas no CRGPL entendem por atenção à saúde, e como avaliam os cuidados recebidos durante o pré-natal, e aqueles destinados aos seus filhos.

Para tanto, consideramos saúde como uma construção social influenciada por vários fatores como: meio ambiente, alimentação, relaçôes sociais, fatores socioeconômicos, dentre outros, para além do acesso a um atendimento médico (SIQUEIRA, 2014). Isto é, neste estudo partimos da premissa de que o conceito de saúde não é algo fixo e pode mudar ao longo dos anos, assim como depende das referências contextuais de cada indivíduo - uma vez que tal concepção depende do entendimento que o indivíduo tem de si mesmo e da sua relação com o meio inserido.

Logo, a análise aqui proposta se guiará a partir do entendimento de que saúde é composta por um tripé: saúde social, saúde psicológica e cuidados com a saúde. Essa escolha vai ao encontro do conceito de saúde proposto pela Organização Mundial da Saúde (OMS, 1946), como um "estado de completo bem-estar físico, mental e social". Assim, este trabalho procura identificar as percepçóes que as internas têm 
do ambiente e das suas relaçôes sociais, as consideraçôes sobre seu estado psicológico e as avaliações sobre os atendimentos médico-hospitalares oferecidos na unidade.

Para tanto, primeiramente apresentaremos uma breve revisão da literatura da área, seguida das notas metodológicas da pesquisa realizada. A abordagem das questôes de saúde na percepção das internas será dividida nas duas seções seguintes: uma sobre o ambiente psíquico-social, e a outra sobre os cuidados de saúde na prisão. Por fim, levantaremos algumas consideraçôes acerca das condiçôes de saúde de gestantes e recém-mães presas no Centro de Referência à Gestante Privada de Liberdade.

\section{Saúde encarcerada: questóes de saúde}

Os estudos que centram a análise na saúde da mulher gestante encarcerada partem da premissa de que o ambiente carcerário tem efeitos na qualidade de vida das internas — uma vez que se encontram em uma situação prejudicial devido à insalubridade do sistema penitenciário - , e que a saúde da mulher grávida também tem influência direta no seu bem-estar durante o cumprimento de pena. Afinal, as mulheres grávidas já passam por situaçôes de mudanças biopsicossociais inerentes à gestação que são acentuadas, muitas vezes negativamente, pelo cárcere (MELLO, 2011). Tendo isso em vista, Braga (2015a) argumenta que, em razão das recorrentes violaçôes de direitos que a privação de liberdade representa, aliada às mudanças impostas pela gestação, toda gravidez vivida na prisão deveria ser considerada uma gravidez de risco.

É importante ressaltar que o cenário prisional nacional é marcado pelas suas condiçôes ambientais precárias, que agravam ainda mais as questôes de saúde de toda a população penitenciária, pela assistência médica muitas vezes insuficiente, e pelas dificuldades com o andamento dos processos judiciais. Diante de todos esses problemas, as gestantes e lactantes, além da maior necessidade de apoio psíquico e social, ainda se preocupam com as demandas próprias da gestação, com as violaçóes de direitos no momento do parto, e com a permanência (ou não) dos filhos no cárcere.

A necessidade de acompanhamento pré-natal é, portanto, uma questáo importante nesse cenário e, no caso brasileiro, podemos citar a análise da realidade de gestantes encarceradas no Rio Grande do Sul. De acordo com Viafore (2005), a realidade da instituição carcerária observada era marcada pela não periodicidade do atendimento pré-natal (que ocorria apenas uma vez durante toda a gestação) e pela dificuldade para o acesso às consultas. A autora destaca ainda que durante a gestação o embrião 
absorve todas as questôes físicas e psíquicas a que é submetida a gestante. Como na prisão as mulheres estão mais susceptíveis a situaçóes de desamparo e estresse, agravados pelo sentimento de angústia inerente ao cárcere, a saúde da gestante e a de seu filho estão ainda mais vulneráveis.

Como contraponto, um estudo sobre a saúde de mulheres grávidas em uma unidade com assistência e acompanhamento médico adequados chama-nos atenção. O estudo de Walker et al. (2014), sobre a saúde das mulheres grávidas encarceradas na Austrália, buscou compreender se a prisão traria uma melhora nos resultados de saúde materna e perinatal tendo em vista um modelo de cárcere "terapunitivo": ou seja, além de punir, a instituição provia assistência médica àquela classe desfavorecida socialmente. A partir de uma pesquisa de corte, fez-se uma comparação entre mulheres que foram presas durante a gestação e mulheres do grupo de controle comunitário - selecionando outras mulheres marginalizadas. Como resultado, as autoras apresentam que, apesar do acompanhamento proporcionado pela unidade prisional, as presas não apresentavam melhorias significativas em relação ao cuidado e atendimento à saúde, além de seus bebês serem os mais propensos a nascerem com baixo peso e serem internados após o parto. Assim, concluem que não há evidências que comprovem que o contato com serviços médicos disponibilizados pela prisão durante a gravidez possa ser considerado uma intervenção terapunitiva, uma vez que se observou uma desvantagem de saúde para as mulheres gestantes encarceradas em relação ao grupo de controle.

Além do atendimento pré-natal, o parto de mulheres presas é tema recorrente de pesquisas da área. O trabalho de Clarke et al. (2013) chama a atenção para a situação de mães e filhos do cárcere nos Estados Unidos da América. Segundo as autoras, nos EUA as gestantes são algemadas tanto no transporte da instituição para o hospital quanto no momento do trabalho de parto, tornando o momento do parto um evento humilhante, doloroso e traumatizante. Além disso, destaca-se nessa abordagem a imediata separação entre mãe e filho, o que acontece 24 horas após o nascimento da criança. Como evidenciado na análise, tais episódios abalam psicologicamente mães e bebês, causando problemas emocionais e até mesmo adoecimento físico.

Com foco na realidade brasileira, em 2016, Leal et al. publicaram uma análise quantitativa das condiçôes e das práticas relacionadas à atenção à saúde de mulheres gestantes e ao parto na prisão. A partir de uma pesquisa em unidades prisionais femininas das capitais e regióes metropolitanas, os dados apresentados permitem 
concluir que apenas $35 \%$ das grávidas privadas de liberdade realizavam o prénatal no país naquele momento. Dentre elas, $66 \%$ consideravam o pré-natal como inadequado ou parcialmente inadequado e, questionadas sobre o trabalho de parto, $35,7 \%$ relataram que na ocasião foram utilizadas algemas. Além disso, apenas 3\% das gestantes presas haviam tido acompanhantes durante o parto - o que, em tese, é direito da mulher ainda que em cumprimento de pena.

Além da oferta de cuidados, outros aspectos da maternidade em situação de privação de liberdade se destacam, e as relaçôes sociais devem, nesse contexto, ser consideradas. É nesse sentido que o estudo de Galván et al. (2006) visa a desvelar como se dá o apoio social às mulheres presas, considerando que esse apoio pode ser a chave para o bem-estar físico e emocional das gestantes dentro dos presídios femininos. A partir de um estudo descritivo na Cidade do México, os autores relacionam a frequência de visitas com a forma que as mulheres percebem a sua saúde dentro da prisão, e com o diagnóstico de depressão. Como resultado, tem-se que as mulheres que não tinham contato com a família tendiam a avaliar negativamente a sua saúde, além de serem as que mais apresentavam quadros depressivos.

Também nesse aspecto, o trabalho de Birolo (2010) no Brasil pode ser mencionado. A autora entrevistou dez detentas de uma ala feminina de um presídio em Santa Catarina, a fim de compreender a vivência do puerpério dentro do cárcere. Ao abordar questóes de saúde, Birolo aponta para a importância dos aspectos sociais e psicológicos, destacando que estes possuem influência direta na saúde das detentas. Apesar das entrevistadas demonstrarem satisfação com o atendimento prestado pontualmente na unidade, questóes como o sentimento de abandono e o distanciamento dos familiares, além das preocupaçôes com o processo e com os filhos que estâo fora da unidade, marcavam negativamente as experiências das mulheres encarceradas.

É diante desse cenário que o presente artigo visa a trazer contribuiçôes para a área, buscando analisar os três prismas - social, psicológico e assistência ao cuidado - concomitantemente. Tendo em vista que este trabalho diz respeito à percepção de mulheres presas, é preciso destacar que a forma como o indivíduo se insere no mundo reflete na forma com que ele o compreende, e esta inserção é marcada por categorias que ajudam a definir esse processo, como raça, gênero, religião, classe social, dentre outros (MACHADO; PORTO, 2015). Assim, as narrativas das entrevistadas expressam visôes de mundo que explicam e atribuem sentido aos 
fenômenos vividos, permitindo-nos, então, acessar a compreensão de mundo daquele agente social marcado por referências próprias. É nessa perspectiva que as impressões das mulheres presas sobre saúde podem, nesta análise, ser apreendidas.

\section{Notas metodológicas}

Tendo em vista os objetivos propostos, este estudo faz uso de uma metodologia mista, utilizando dados coletados em entrevistas semiestruturadas com sete presas do CRGPL, assim como dados coletados a partir da aplicação de questionários estruturados 2 . O trabalho de campo foi viabilizado pela pesquisa "Amor bandido é chave de cadeia?", executada por pesquisadoras do Centro de Estudos de Criminalidade e Segurança Pública (CRISP/UFMG) com financiamento da FAPEMIG (APQ-01648-16), entre os meses de julho e outubro de $2017^{3}$.

Para contemplar a perspectiva qualitativa, foram feitas visitas in loco para realização de entrevistas semiestruturadas com três mulheres gestantes e quatro lactantes. É importante destacar que as internas eram encaminhadas pelas agentes prisionais de acordo com sua disponibilidade - o que pode, de alguma forma, refletir nos dados apresentados, mas é importante ressaltar que nenhuma agente prisional acompanhou as presas durante as entrevistas, garantindo assim sigilo e confidencialidade dos relatos.

Uma vez apresentadas à equipe, as mulheres selecionadas passavam a ter conhecimento do estudo e então aceitavam, ou não, conceder entrevista às pesquisadoras. É válido dizer, ainda, que todos os depoimentos foram gravados, com expressa autorização das entrevistadas, a fim de facilitar a análise dos dados. As entrevistas consentidas foram transcritas e codificadas com a ajuda do software N-VIVO. Outro ponto a ser destacado é que as entrevistas foram, para este artigo, numeradas de 1 a 7 , como forma de preservar a identidade das internas.

Sob a perspectiva quantitativa, este estudo conta com a aplicação de questionários a 25 internas de um total de 51 no momento da pesquisa. É válido, aqui, esclarecer dois pontos: este foi o maior número de voluntárias que a equipe conseguiu para a realização desta parte da pesquisa, e o survey foi aplicado também sem a supervisão ou presença de agentes prisionais. A presente análise é composta pelos dados processados com a ajuda do software SPSS, e por alguns relatos compartilhados pelas internas durante essa fase. 
Por fim, e para melhor compreensão dos limites e das possibilidades dos dados aqui analisados, é importante identificar o perfil das internas que participaram da pesquisa, pois ele nos revela quem está falando e sob quais condições, embasando as impressôes que as mulheres presas no CRGPL apresentam sobre os cuidados de saúde. Tendo em vista a metodologia mista e a fim de identificar os resultados das duas frentes de investigação, denominamos "entrevistadas" as mulheres que participaram da parte qualitativa do referente estudo, e "respondentes" as internas que compóem o banco de dados quantitativo da pesquisa.

As entrevistadas têm entre 21 e 31 anos de idade, o que se assemelha aos dados quantitativos: as respondentes tinham entre 19 e 33 anos, correspondendo a uma média de 25. Em relação à cidade de origem dessas mulheres, há uma consonância nos dados, sendo a maioria não residente em Belo Horizonte, como é possível visualizar abaixo. Isso ocorre porque todas as mulheres grávidas ou mães de recémnascidos presas em outros presídios de Minas Gerais são transferidas para o Centro, por esta ser a única unidade materno-infantil do estado.

\section{Gráfico 1. Distribuiçẫo das mulheres de acordo com a cidade de origem}

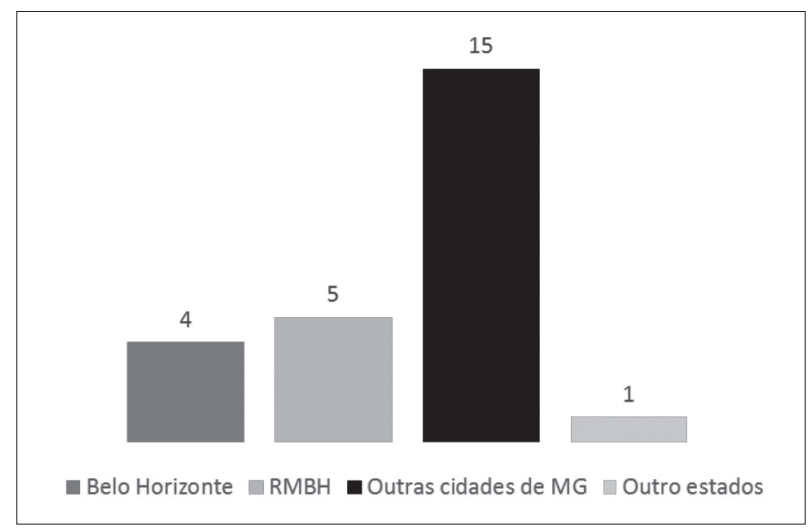

Fonte: “Amor bandido é chave de cadeia?” (CRISP)

Éimportante ainda destacar a situação processual das internas: 56\% das respondentes do survey eram presas provisórias e, no caso das sete entrevistadas, quatro mulheres estavam nessa mesma situação. Quanto às presas condenadas, a maioria respondia pelo crime de tráfico de drogas. Dados estes que correspondem ao perfil da maioria da população carcerária feminina no Brasil, conforme dados do Infopen (2016). 


\section{As narrativas sobre o ambiente psíquico-social}

No roteiro das entrevistas semiestruturadas o bloco de perguntas sobre saúde iniciava com uma questão sobre o que elas entendiam por saúde. Inicialmente, algumas julgavam não saber conceituá-la, porém sabiam se posicionar quando perguntadas se o ambiente proporcionava a elas uma vida saudável. Dentre as várias conceituaçôes respondidas, seguem duas emblemáticas:

Entrevistadora - Mas pensando em saúde, assim em ter saúde e estar saudável, não é? Você acha que esse lugar te proporciona uma vida com saúde, uma vida saudável, aqui no centro?

Entrevistada 3 - Não [...]. Porque a casa da gente é melhor, eu acho. Eles ajudam muito, tem saúde aqui, toda hora que você precisar de remédio, eles dão. Mas a casa da gente é melhor, eu acho. Você pode ficar mais saudável na sua casa.

Entrevistadora - E um pouquinho sobre saúde.... Você acha que a vida que vocês levam aqui é uma vida saudável, está tudo bem?

Entrevistada 7 - Ah, para mim está tudo bem, é que lá na rua eu estava bebendo, estava fumando, aqui eu não estou fazendo isso.

Das definiçóes apresentadas, destacam-se duas diferentes percepçóes sobre saúde que refletem justamente a realidade das entrevistadas como ponto de referência. No texto de Câmara et al. (2012), é ressaltado que o entendimento sobre saúde é dado em seu contexto sociocultural, assim, o conceito vai variar de acordo com a cultura local, o momento histórico e as condiçôes da existência, assim como com as experiências individuais marcadas por estes fatores. As falas anteriores demonstram justamente essa explicação: enquanto a entrevistada 3 remete ao apoio que receberia no ambiente familiar e que lhe faz falta na cadeia, a entrevistada 7 ressalta hábitos não saudáveis de sua vida que, na prisão, são inviabilizados.

Assim, as premissas psicológicas, sociais e físicas também emergem nos discursos das entrevistadas, tal como se embasou a pesquisa de Birolo (2010) para analisar a saúde das mulheres em uma ala feminina. O primeiro parâmetro apresentado por Birolo é o ambiente psicológico, em que são consideradas as questóes que ocupam a mente das internas, como o trabalho e as preocupaçóes que elas venham a ter dentro do cárcere. Reafirmando a importância do aspecto psicológico, Paíno Quesada et al. (2007) enfatizam que o cárcere por si já é um local propício a potencializar a ansiedade, dada a perda de identidade, a perda de autonomia, e a incerteza sobre o futuro. Nesta perspectiva, Viafore (2005) pontua ainda que a gestação é um 
momento de intensas transformaçôes corporais e emocionais vividas pelas mulheres, e a prisão agravaria o quadro de ansiedade e de preocupaçôes, por exemplo, com relação à situação processual.

No Centro o acompanhamento do processo é feito mensalmente junto com o advogado da unidade, fazendo com que as mulheres se sintam um pouco mais tranquilas com relação às questôes processuais. Porém, nossas entrevistas foram realizadas durante o período de férias desse profissional e sem indicação de um defensor substituto, motivo pelo qual as entrevistadas já apresentavam relativa preocupação com seus casos. Pesa também o fato de a maior parte das entrevistadas, como dito, ser presa provisória e ainda estar aguardando o seu julgamento. Isso intensifica a afliçâo com que vivem os dias no cárcere, como relata a entrevistada 1: "Ah, minha vida dentro daqui minha filha... É só... Todos os dias, eu acho que eu ouço meu nome cantando no alvará. Mas infelizmente. [...] E essa ansiedade dentro de mim?”.

Além das angústias causadas pelo andamento - e muitas vezes, pelo desconhecimento - de seu processo, Ventura et al. (2015) enfatizam que a guarda dos filhos é também uma questão de inquietação psicológica para essas mulheres, que se preocupam em como e com quem suas crianças ficarão após o período que a instituição permite o contato entre ela e o bebê. Nos estudos de Birolo (2010), a separação da mulher com sua criança emergiu como uma preocupação constante entre as internas, que relataram o momento da separação como muito doloroso. A delicadeza deste assunto aparece também em estudos internacionais, como no trabalho de Clarke (2013). As autoras pontuam que o crescente número de encarceramento feminino fez com que alguns estados dos EUA voltassem a considerar questôes sobre a permanência da mãe com o filho, já que a separação é um evento devastador para ambos.

No Centro, apesar de todas as mulheres entrevistadas terem dado início ao processo de tutela ou já terem decidido quem indicarão para a guarda do filho, esse é um assunto sobre o qual elas não se sentiam confortáveis para falar. O desconforto e a angústia em pensar na separação do bebê, ou no possível encaminhamento da criança para outro lugar, são demonstrados por todas as entrevistadas quando abordamos esse assunto.

Entrevistadora - E como você acha que vai ser quando seu neném sair daqui?

Entrevistada 1- Eu vou embora para casa, gente, pelo amor de Deus, em nome de Jesus. Eu.... Eu fico, assim, nessa esperança de ir embora. Até mesmo antes de ganhar, mas se 
for da vontade de Deus, não é?! Se for permissão. Se o juiz entender que eu tenho que pagar meu erro.

Entrevistadora - E você já pensou se ela tiver que.... Se você tiver que ficar e ela tiver que ir, você já pensou nisso, com quem ela vai ficar?

Entrevistada 1 - Já, com minha mãe.

Dizer que sairão com seus filhos, é na verdade, uma forma de evitar discutir tal momento. $\mathrm{Na}$ análise quantitativa, como se pode observar a seguir, destaca-se o número de respostas imbuídas de esperança - e desconforto, como relata a equipe que esteve em campo:

Gráfico 2. Distribuição das mulheres de acordo com a guarda do(a) filho(a) quando sair do CRGPL

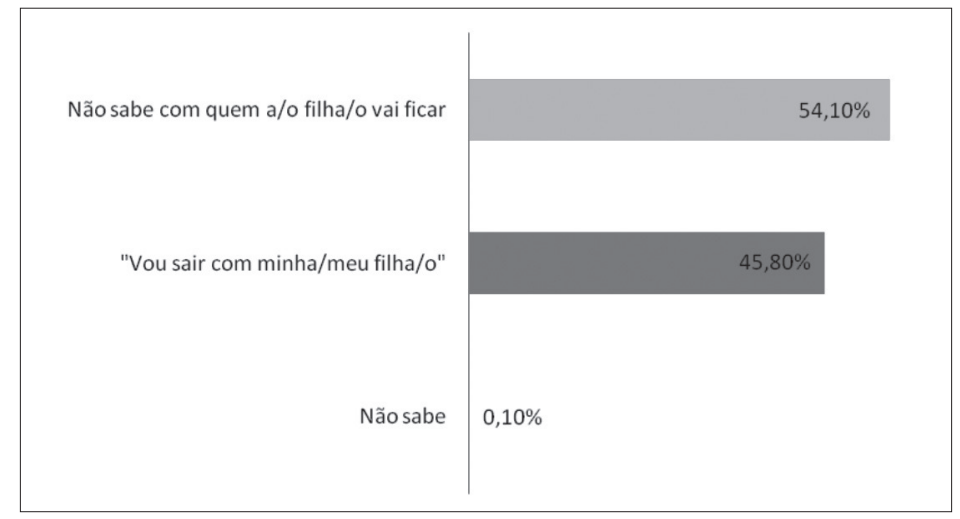

Fonte: Amor bandido é chave de cadeia? (CRISP)

O fato de a maioria das entrevistadas ter filhos fora da prisão aumenta ainda mais o sofrimento dessas mulheres, o que é também destacado na análise de Cerneka (2009). Na maior parte das vezes, essas mães não sabem com quem e como estão os seus filhos, aumentando o peso da pena a elas imposta. Essa preocupação fica mais latente quando o responsável legal perde a guarda do filho da detenta, fazendo com que a criança passe a ser custodiada pelo Estado. Como pode ser percebido no relato emocionado da entrevistada 5: "E a gente está privada da liberdade, não pode estar fazendo nada para evitar que isso venha acontecer, não é?! A gente só entrega na mão de Deus e espera que dias melhores venham, não é?! Que a gente vai sair daqui, pensar positivo e seguir a vida e conseguir tirar eles de lá.” 
Dentre as 7 internas entrevistadas, 5 tinham filhos fora da prisão. E no caso daquelas que responderam ao questionário, $57,10 \%$ das mães moravam com seus filhos antes do aprisionamento.

Gráfico 3. Distribuição das mulheres de acordo com a existência de outro(s) filho(s) fora da prisão

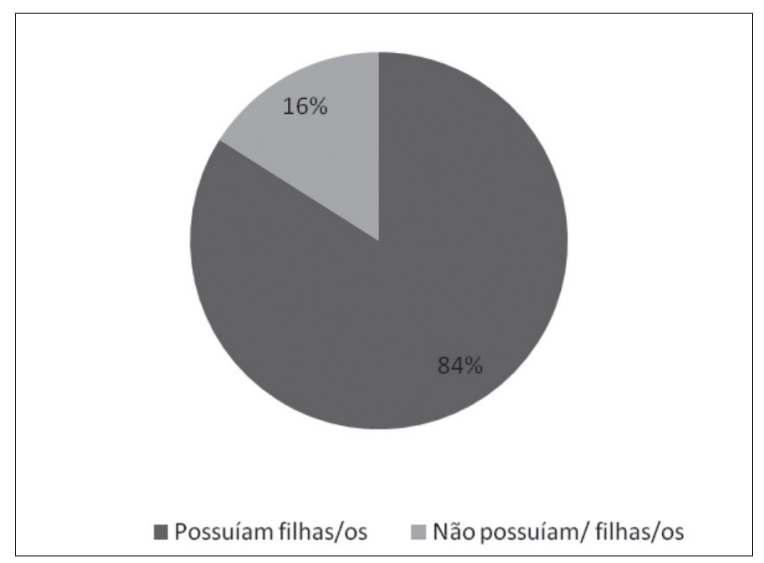

Fonte: Amor bandido é chave de cadeia? (CRISP)

Outro fator que se reflete no bem-estar psicológico das mulheres presas é a relação com o trabalho na unidade. Segundo Birolo (2010), o trabalho pode atenuar as dores e ansiedades da prisão ou, em excesso, potencializar o sofrimento da mulher na prisão. No Centro, para além da oportunidade de trabalharem como artesãs, cuidadoras de crianças e cozinheiras, as internas são as responsáveis pela limpeza integral da unidade, sendo este um ponto de grande incômodo para as detentas, como é observado na fala de uma das entrevistadas, que conta que são três turnos de limpeza:

Entrevistada 5 - Porque aqui a gente trabalha muito, não é? Assim, porque a gente tem que fazer a faxina do convívio, entáo assim todos os serviços de meio-dia são lavados, são lavados com água e sabão, e assim [...] isso aí a gente não tem remissão, isso aí é obrigatório a gente fazer, e aí limpa sete da manhá, meio-dia, lava tudo, limpa tudo e as dezoito, não é? [...] aí aonde que a gente vai tem que levar as crianças porque as cuidadoras não ficam com as crianças para a gente ir lá limpar a unidade.

Além da alta carga de trabalho - que não respeita o período de resguardo, como relatado por uma entrevistada - o que mais é questionado pelas detentas é a obrigatoriedade de levarem seus filhos ao local em que estão realizando a limpeza, 
por mais que isso exponha o bebê à sujeira, a materiais tóxicos, ou lhe provoque choro. Desta forma, para algumas entrevistadas, o trabalho de faxina na unidade se torna prejudicial à saúde psicológica da mãe e, por vezes, à saúde física do filho.

A regra de levarem consigo a criança para todos os lugares, inclusive durante a limpeza, é apenas uma das inúmeras regras às quais essas mulheres são submetidas, e que acabam moldando a relação entre mãe e filho. Algumas delas são: se o filho chorar, as mães recebem comunicado (uma espécie de puniçâa), todas as mulheres são obrigadas a amamentar, as mães não podem dormir na cama com o seu filho, nem deixar que andem no chão. A maternagem ${ }^{4}$ na instituição, condicionada pelas regras, se torna uma forma de adoecimento psicológico para algumas mulheres. As entrevistadas não concordam com todas as regras impostas e reclamam dessas condiçóes, mas se submetem a elas para permanecerem com seus filhos.

Além de permeados pela disciplina e tutelados pela instituiçáo prisional, o exercício da maternidade e a relação com os filhos que estão dentro da prisão são sempre uma questão delicada para estas mulheres. É com os filhos que elas se relacionam com maior frequência e intensidade, ficando integralmente com suas crianças em um processo de hipermaternidade (BRAGA; ANGOTTI, 2015b). E esse relacionamento é ainda perpassado pelo sofrimento antagônico da mãe que vive com o filho na prisão, uma vez que ele também está encarcerado, e pelo sofrimento da mãe que não convive - ou deixará de conviver - com seu filho, por ela estar encarcerada (VIAFORE, 2005).

Em uma conversa informal com uma interna do Centro, ela foi enfática ao dizer "se tirarem meu bebê de mim eu morro, ele que me dá força para aguentar isso daqui”. Esta frase diz muito da relação da mulher com seu filho na prisão: a criança é a principal relação afetiva e de plena confiança que elas têm na unidade, se tornando até mesmo a única relação social destas mulheres. Além de filho, o bebê se torna o único apoio emocional e até mesmo uma oportunidade de estar em um lugar melhor que o "cadeião", como dito:

Entrevistada 6 - Se não fosse ela, eu não estaria aqui, eu estaria no cadeião tomando banho de água fria, eu estaria no cadeião comendo comida às vezes até azeda porque, não é?! Todos os cadeiōes são de qualquer jeito e aqui não, tudo é direitinho por causa das crianças, tudo que eles fazem aqui é pensando nas crianças.

A intensidade da relação entre mãe e filho encarcerados também se dá pelo distanciamento do convívio familiar da mulher presa (BIROLO, 2010; CATITO, 
2015. Nesse sentido, Galván et al. (2006) apontam que o cárcere se torna ainda mais estressante para as mulheres, por significar o afastamento e a separação forçada de entes queridos, principalmente de seus filhos que estão fora da prisão. As relaçóes sociais são, nesse contexto, permeadas por diversas privaçóes. A ausência da família e dos companheiros e/ou dos pais das crianças já foi muito abordada na literatura, e é também nítida dentro do CRGPL.

Das sete mulheres entrevistadas, apenas duas continuavam com seus companheiros, mas não os encontravam porque também estavam presos; então, mantinham contato através de cartas. Em relação ao contato com os familiares, apenas três presas disseram receber visita, enquanto as outras quatro justificaram a ausência dos entes queridos ou pela distância - já que as detentas são transferidas de suas cidades, que não contam com infraestrutura prisional para gestante -, ou pela preocupação com o bem-estar do familiar - que, além do esforço, pode sofrer constrangimento. Os dados quantitativos confirmam a ausência de visitas às internas do Centro. Dentre as 25 mulheres que responderam ao questionário, apenas quatro recebiam visitas das mães, uma recebia do pai, duas recebiam de seus companheiros(as), e três de irmãs(os). Nenhuma das respondentes recebia visita de seus filhos e filhas.

Vista a ausência de visitas, no Centro há duas fontes de contato entre as mulheres e os seus familiares, o que as ajuda, de alguma forma, a viver no cárcere: os telefonemas e o Sedex. Toda mulher na unidade tem direito a realizar uma ligaçáo de 6 minutos a cada 15 dias para um número à sua escolha - e esse direito, em um contexto de tantas privações, é percebido por elas como uma regalia oferecida pela unidade. Já o Sedex são os itens enviados pela família para suprirem as necessidades das detentas e, apesar de não ser de fato um contato, é muitas vezes o único sinal de amparo que essas mulheres têm de suas famílias. Das entrevistadas, quatro recebem o Sedex da família, mas ponderam que o recebem apenas com itens para criança. De acordo com a pesquisa quantitativa, $60 \%$ das internas contavam com esse apoio familiar.

Apesar das críticas e insatisfações levantadas pelas internas, o ambiente psíquicosocial do Centro é visto de forma razoavelmente positiva pelas entrevistadas e tal percepção se dá devido a dois fatores: a comparação com a vida na prisão comum, o chamado "cadeiáo", e a possibilidade de estar junto de sua criança, que se torna sua grande companhia. Nas falas das entrevistadas 6 e 4, respectivamente, temos: "[...] Alimentação muito boa, tratamento é bom, não tem injustiça, o que eles podem 
fazer pela gente, eles fazem, entendeu?! Para mim não é como uma cadeia”, “[...] aqui nós estamos com nosso filho. Em cadeião a gente não tem isso não".

\section{As percepçóes sobre os cuidados de saúde}

Para além das questóes psicossociais, o cuidado da saúde também é composto pela oferta de atendimento e acesso a serviços de saúde. Esse aspecto é o grande foco do Centro, que foi justamente idealizado para prestar atendimento de qualidade a gestantes e lactantes e seus filhos. Na unidade, há uma equipe de saúde formada por uma psicóloga e uma assistente social que atendem as internas mensalmente, uma dentista que as atende quando solicitada, e duas enfermeiras que, junto com quatro técnicas de enfermagem, se revezam para uma assistência 24 horas por dia. Enquanto os atendimentos mensais são marcados, o atendimento com a dentista e com as enfermeiras é realizado após cada interna o solicitar para a agente prisional, que é responsável por encaminhar as demandas a esses profissionais. As sete entrevistadas se mostraram satisfeitas nesse sentido, alegando que "é só pedir que você recebe o atendimento". Assim, as internas têm uma rotina de atendimento, e as questóes emergenciais que são solicitadas através das agentes podem ser atendidas tanto pelas enfermeiras quanto pelos profissionais "de fora", sendo que as internas podem ser encaminhadas para hospitais ou postos de saúde.

Quando é necessário um médico geral ou especialista, a enfermeira encaminha para hospitais ou postos de saúde, e o pré-natal é realizado pelos profissionais "de fora”: nesse caso pela equipe do Hospital Sofia Feldman, que tem uma grande relação de parceria com o Centro, tanto nos cuidados das mulheres, como na assistência ao parto e no cuidado da criança após seu nascimento. As entrevistadas têm grande confiança nas profissionais do presídio e também na equipe do hospital, que é considerada a "da rua" ou "de fora". Ela está presente semanalmente no Centro realizando o pré-natal das crianças, e é para o Sofia que as detentas são encaminhadas para o pré-natal de risco e para o parto. O acompanhamento de pré-natal é iniciado imediatamente quando a mulher chega à unidade, e os exames necessários são realizados pelo mesmo hospital, não havendo, para as sete entrevistadas, nenhuma dificuldade nesse processo, que elas julgam bastante satisfatório.

O Hospital Sofia Feldman é uma unidade de assistência materno-infantil com todos os seus leitos destinados ao Sistema Único de Saúde, e é reconhecido 
nacionalmente por ser modelo de atendimento pelo SUS e exemplo de humanização na saúde. A política de parto no Sofia é a preferência pelo parto normal, com alguma interferência apenas se necessário. Mas como há a cultura de cesárea no Brasil, o parto normal às vezes é visto como uma preocupação para a interna, que por vezes entende que a obrigatoriedade do parto normal é mais uma forma de punição que ela vive em cárcere.

Tendo em vista os relatos coletados para este estudo, em certa medida, por trás de algumas preocupaçóes ou descontentamentos com o parto normal, mesmo que seja o procedimento comum no cárcere brasileiro, está o direito de escolha que é negado à mulher privada de liberdade. Nesse sentido, estar encarcerada significa estar privada de inúmeras escolhas, e essa falta de autonomia fica evidente quando se trata das questóes mais pessoais da sua vida, tal como o parto. E, nesse aspecto, a presença de agentes prisionais durante o parto é ainda mais ressaltada pelas entrevistadas. Na contramáo da Lei $11.108^{5}$, instituída em 2005, que garante que toda gestante tenha um acompanhante de sua escolha no momento do parto, às internas do Centro não são permitidos acompanhantes escolhidos por elas, e isso então é feito por agentes prisionais. Essa realidade é relatada também por Leal et al. (2016) como mencionado anteriormente.

Entrevistadora - E no seu parto, como que foi seu parto?

Entrevistada 5 - Nó! Muito doloroso. [...] É, todos os meus meninos nasceram de parto normal, mas assim é diferente, não é? Eu não estava me sentindo à vontade com guarda dentro, dentro da sala, não. [...] aí ela custou nascer porque...

Neste sentido, o pano de fundo das reclamaçóes é justamente a falta de autonomia da mulher presa. Como colocado por Lopes e Pinheiro (2016), o sistema penal é o espaço em que a mulher não tem autonomia para fazer suas escolhas, dado que a trajetória do cuidado é definida pela lógica do sistema, que não propicia um diálogo e nem possibilidades de abertura, em especial no momento do parto.

Além dessa questão, outra grande reclamação é sobre a ausência do médico na unidade, que havia saído do Centro há algum tempo. Nesse ponto, é preciso ponderar que a necessidade de o médico aparecer, como uma questão significativa e recorrente nas entrevistadas, reflete, em certa medida, a centralidade que este profissional tem no entendimento de saúde no Brasil. Daí porque essa ausência é tão sentida pelas mulheres, mesmo com a presença integral de enfermeiras na unidade e o encaminhamento para atendimento externo. 
Há, nesse sentido, queixas importantes a serem consideradas quando tratamos do atendimento de saúde no Centro, apesar de haver assistência médico-hospitalar adequada com relação ao pré-natal, ao parto e ao puerpério. Outros pontos levantados na pesquisa foram: a alimentação, a atividade física e o acesso a medicamentos. As entrevistadas reafirmaram sua satisfação com relação à comida, e a atividade física, apesar de ausente, não apareceu sequer como um direito reclamado. Com relação ao provimento de medicamentos para as mães, as mulheres se julgavam suficientemente atendidas.

Todavia, as questóes mais problemáticas apareceram quando tratávamos dos atendimentos às suas crianças. As reclamaçóes sobre os cuidados das crianças foram sobretudo com relação à ausência do pediatra na unidade e à indisponibilidade dos medicamentos necessários - o que obrigava as famílias a terem que providenciar Sedex com itens de saúde ou higiene de que a instituição não dispunha. Uma das entrevistadas nos relatou a importância das outras internas nesses casos, que muitas vezes oferecem doaçóes em dinheiro para arcar com os gastos dos bebês que não recebem assistência familiar, seja para compra de remédios e itens de higiene específicos, seja para os custos de exames que o CRGPL não consegue prover. $\mathrm{E}$ nesse aspecto, para as entrevistadas, o Centro precisava de um pediatra próprio, que atendesse às demandas dos bebês. Para as algumas internas, elas "precisam conseguir no grito" ou as agentes "precisam ver que a criança está doente", para que fossem encaminhadas ao atendimento externo. Apesar de não serem discursos recorrentes, e nem mesmo da maioria, essas reclamaçóes apareceram - o que não aconteceu quando tratamos especificamente da saúde da mulher.

Por fim, vale dizer que, se por um lado alguns problemas são levantados pelas internas do Centro, por outro, a prestação de serviços de saúde na unidade contrasta com os dados apresentados em pesquisas nacionais - que demonstram que as mulheres e suas crianças encarceradas não têm, em sua maioria, acesso nem ao atendimento básico de saúde. Exatamente por isso, as entrevistadas compararam a todo tempo a sua situação no CRGPL com as más condições vivenciadas por outras mulheres presas, ou por elas mesmas em outras instituiçôes prisionais, como é o caso da entrevistada que cita sua experiência no Complexo Penitenciário Estevão Pinto (PIEP):

Entrevistadora - Você sente muita diferença entre o seu acompanhamento médico quando você estava presa na PIEP e aqui quando você estava grávida? 
Entrevistada 6 - Porque na PIEP você sendo de alto risco ou não você trata na unidade, entendeu? Aqui não, eles te dáo mais oportunidade, você vai direto para o hospital onde eles têm capacidade para o seu problema.

Como abordado, para compreender a avaliação consideravelmente positiva que as internas fazem do Centro, é preciso considerar a trajetória de violaçóes de direitos das mulheres entrevistadas, seja nas suas experiências no sistema prisional, seja nas suas trajetórias de vida. A percepção do atendimento à saúde - desde a alimentação até os cuidados médicos - passa, em última instância, por essas referências. Assim, as comparaçôes são vívidas em suas memórias e em suas narrativas.

\section{Considerações finais}

Tendo em vista os resultados da pesquisa realizada no Centro de Referência à Gestante Privada de Liberdade, tal como posto no decorrer da análise, é válido destacar alguns pontos. Com o objetivo de analisar as condiçóes de saúde social, psíquica e física das internas do CRGPL, com este estudo pode-se compreender que, para além dos atendimentos de saúde da mulher, são os temas relacionados aos cuidados dos filhos e ao exercício da maternidade em condiçôes de privaçáo de autonomia, de recursos materiais e de relaçôes sociais confiáveis que tornam a vida de mães e filhos no cárcere ainda mais delicada.

Fica evidente, ainda, que a percepção das internas com relação às questôes de saúde na unidade é perpassada pelas recorrentes comparaçóes com as demais unidades prisionais. Nesse aspecto, vale destacar também que o Centro foi criado após anos de discussôes sobre a realidade de extrema vulnerabilidade de mulheres gestantes no Brasil, além de esforços em políticas públicas para a superação desta realidade. Em vista do que é abordado na literatura, o CRGPL se destaca no cenário nacional por prover um maior acesso a cuidados dessa população carcerária específica, apesar de alguns pontos bastante críticos - como os que foram levantados neste debate.

É nesse contexto que é possível considerar que, apesar de apresentar diversos problemas no que tange aos cuidados de saúde psicossocial e médica, a unidade materno-infantil mineira cumpre parte das expectativas e das necessidades das mulheres gestantes e mães em cumprimento de pena no estado. Eé, portanto, diante dessas condiçóes que as impressóes das internas sobre os cuidados de saúde no Centro não são, de maneira geral, negativas. De acordo com o olhar tanto das entrevistadas, 
como das respondentes na pesquisa realizada, foram destacados pontos positivos do Centro, mas há também questôes importantes para a vida no cárcere que, segundo elas, têm sido negligenciadas e, sobretudo, que têm causado sofrimento e problemas de saúde em mulheres e crianças.

Dito de outro modo, as diversas violaçóes de direitos que mulheres presas no país vivenciam e as difíceis experiências de vida dessa populaçấo - marcadas por contextos de vulnerabilidades - não podem servir como parâmetro para minimizar a urgência em tratar e acolher de maneira diferente as gestantes e mães aprisionadas no Centro de Referência à Gestante Privada de Liberdade. O atendimento integral e de qualidade dos cuidados de saúde psicossocial e física necessários é tão essencial como a estrutura específica que uma unidade materno-infantil exige. É nesse sentido que destacamos, por fim, que a assistência médico-hospitalar direcionada à mulher e ao bebê são fundamentais, tanto quanto as questôes que reverberam na saúde psicológica e no convívio social das encarceradas. ${ }^{6}$

\section{Referências}

BIROLO, I. V. B. Puerpério em ambiente prisional: vivência de mulheres. Dissertação (Mestrado em Enfermagem) - Universidade Federal de Santa Catarina, Florianópolis, 2010.

BRAGA, A. G. M. et al. Dar à luz na sombra: condiçóes atuais e possibilidades futuras para o exercício da maternidade por mulheres em situação de prisão, Brasília, 2015a (Série Pensando o Direito, 51).

BRAGA, A. G. M.; ANGOTTI, B. From hyper-maternity to hypo-maternity in women's prisons in Brazil. SUR 22, v. 12, n. 22, p. 229-239, 2015 b.

BRASIL. Lei Federal no 11.108, de 7 de abril de 2005. Lei de Execução Penal (LEP). Disponível em: <http://www.planalto.gov.br/ccivil_03/_ato2004-2006/2005/lei/111108.htm>. Acesso em: 24 nov. 2017.

. Lei Federal no 11.942, de 28 de maio de 2009. Lei de Execução Penal (LEP). Disponível em: <https://www2.camara.leg.br/legin/fed/lei/2009/lei-11942-28-maio-2009588524-publicacaooriginal-113114-pl.html>. Acesso em 30 mar. 2020.

. Lei Federal no 13.257, de 8 de março de 2016. Disponível em <http://www.planalto. gov.br/ccivil_03/_ato2015-2018/2016/lei/113257.htm>. Acesso em: 7 fev. 2018.

. Lei Federal no 7.210 de 11 de julho de 1984. Lei de Execuçáo Penal (LEP). Do Objeto e da Aplicação da Lei de Execução Penal, Lei Orgânica da Assistência Social (LOAS, 1993). Disponível em: <http://www.planalto.gov.br/ccivil_03/leis/L7210.htm>. Acesso em: 20 nov. 2017. 
Ministério da Saúde. Plano Nacional de Saúde no Sistema Penitenciário (PNSSP). Brasília: MS, 2004. Disponível em: <http://bvsms.saude.gov.br/bvs/publicacoes/cartilha_ pnssp.pdf>. Acesso em: 20 nov. 2017.

CAMARA, A. M. C. S. et al. Percepção do Processo Saúde-doença: significados e valores da educação em saúde. Revista Brasileira de Educação Médica, v. 41, n. 36, supl. 1, p. 40-50, 2012.

CATITO, F. G. L. Depressão e sofrimento emocional durante a gravidez e separação dos filhos em mulheres encarceradas no Estabelecimento Prisional Feminino de Viana em Luanda, Angola. 2015. Dissertação (Mestrado em Psicologia) - Pontifícia Universidade Católica de São Paulo, São Paulo, 2015.

CERNEKA, H. A. Homens que menstruam: consideraçôes acerca do sistema prisional às especificidades da mulher. Veredas do Direito, Belo Horizonte, v.6, n. 11, p. 61-78, jan-jun 2009.

CLARKE, J. G. et al. Shackling and Separation: Motherhood in Prison Virtual Mentor, v. 15, n. 9, p. 779-85, Sept. 2013.

GALVÁN, J. et al. La importancia del apoyo social para el bienestar físico e mental de las mujeres reclusas. Salud mental, v. 29, n. 3, mayo-junio, 2006.

LEAL, M. C et al. Birth in prison: pregnancy and birth behind bars in Brazil. Ciência \& Saúde Coletiva, v. 21, n. 7, 2016.

LOPES, T. C.; PINHEIRO, R. Trajetórias de 1.193 mulheres privadas de liberdade: práticas de cuidado no reconhecimento do direito à saúde no Centro de Referência de Gestantes de Minas Gerais. Physis: Revista de Saúde Coletiva, Rio de Janeiro, v. 26, n. 4, p. 1193-1212, 2016.

MACHADO, B. A.; PORTO, M. S. G. Homicides in the metropolitan area of Brasilia, DF: social representations by Police Chiefs, prosecutors and judges. Sociologias, v. 17, n. 40, p. 294$325,2015$.

MELLO, D. C.; GAUER, G. Vivências da maternidade em uma prisão feminina do estado Rio Grande do Sul. Saúde \& Transformação Social, v. 2, n. 2, p.113-121, 2011.

ORGANIZAÇÃO MUNDIAL DA SAÚDE. Constituição da Organização Mundial da Saúde. Conferência Internacional de Saúde, Nova York, 19-22 jul. 1946.

PAÍNO QUESADA, S. G. et al. Vivencia de la maternidad en la privación de libertad y niveles de ansiedad. Un estudio en el centro penitenciario de Odemira (Portugal). Anuario de Psicología Juridica. Madrid, v. 17, p. 65-78, 2007.

SIQUEIRA, N. L. Gênero e saúde no Brasil: a (re)produção de desigualdades. Dissertação (Mestrado em Sociologia) - Faculdade de Filosofia e Ciências Humanas, Universidade Federal de Minas Gerais, Belo Horizonte, 2014.

VIAFORE, D. A gravidez no cárcere brasileiro: uma análise da Penitenciária Feminina Madre Pelletier. Direito \& Justiça, v. 31, n. 2, 2005. 
VENTURA, M. et al. Maternidade atrás das grades: em busca da cidadania e da saúde. Um estudo sobre a legislação brasileira. Cad. Saúde Pública, Rio de Janeiro, v. 31, n. 3, p. 607-619, mar. 2015.

WALKER, J. R. et al. Pregnancy, prison and perinatal outcomes in New South Wales, Australia: a retrospective cohort study using linked health data. BMC Pregnancy and Childbirth, v. 14, n. 214, 2014. doi: 10.1186/1471-2393-14-214.

\section{Notas}

${ }^{1}$ Os últimos anos foram marcados pelo crescimento da população prisional brasileira, que, entre 1999 e 2016, teve um aumento de $274 \%$. Destaca-se, sobretudo, o número de presas no país: no mesmo período, as taxas de aprisionamento feminino cresceram mais de 500\%. Esse aumento reflete no número de mulheres gestantes e recém-mães privadas de liberdade no país. De acordo com dados do Infopen (2018), em 2016 o Brasil contava com 536 detentas gestantes e 350 lactantes presas. No entanto, apenas 14\% das unidades prisionais tinham, naquele momento, berçário e/ou centro de referência materno-infantil.

${ }^{2}$ Parte da análise das entrevistas citadas foi minuciosamente desenvolvida em outro trabalho de mesma autoria.

${ }^{3}$ A pesquisa foi aprovada pelo Comitê de Ética da Universidade Federal de Minas Gerais (CAAE: 84242418.4.0000.5149).

${ }^{4}$ A maneira como a mulher exerce sua maternidade.

5 “Art. 19-J. Os serviços de saúde do Sistema Único de Saúde - SUS, da rede própria ou conveniada, ficam obrigados a permitir a presença, junto à parturiente, de 1 (um) acompanhante durante todo o período de trabalho de parto, parto e pós-parto imediato. $\$ 1$ o $\mathrm{O}$ acompanhante de que trata o caput deste artigo será indicado pela parturiente. $\$ 2$ o As açóes destinadas a viabilizar o pleno exercício dos direitos de que trata este artigo constaráo do regulamento da lei, a ser elaborado pelo órgão competente do Poder Executivo".

${ }^{6} \mathrm{~L}$. H. Chaves coordenou o trabalho de campo, auxiliou na análise dos dados, na redação do texto final e, sendo bolsista de pós-doutorado, o presente trabalho foi realizado com apoio da Coordenação de Aperfeiçoamento de Pessoal de Nível Superior - Brasil (CAPES). I. C. A. de Araújo participou do trabalho de campo, da construção da análise de dados e da redação da versão final do artigo. 


\section{Abstract}

Pregnancy and maternity in prison: healthcare from the perspective of women imprisoned in a maternal and child unit This article presents results of a research carried out in the maternal and child prison unit in the State of Minas Gerais. In order to deal with the impressions that women imprisoned in the Reference Center for Pregnant Women in Private Liberty (CRGPL) have on health care offered by the institution, the processed data were analyzed from semi-structured interviews and structured questionnaires. The research was conducted in 2017, and the analysis proposed in this study is guided by the understanding of the concept of health from the "social, psychological and health care assistance" standpoint, from the perspective of social representations. As a result, there is a certain positive evaluation of health care from the perspective of pregnant women and new mothers at the Center, and this is marked, according to reports, by the previous prison experiences of the interviewees. However, some problems faced in the CRGPL were raised by the inmates, and described as a source of several sufferings.

Keywords: health; maternity; pregnancy; female prison. 